\title{
Early Outcomes of Arterial Switch Operation Performed at a New Pediatric Cardiology Center in Mumbai
}

\author{
Bhadra Trivedi ${ }^{1, ~ *, ~ P r a s a n n a ~ S a l v i ², ~ M a n i s h ~ C h o k h a n d r e ', ~ N a v e e d ~ K h a n ~}{ }^{2}$, Ameya Mandrekar $^{2}$, \\ Suresh Joshi $^{3}$ \\ ${ }^{1}$ Department of Pediatric Cardiology, Wockhardt Hospitals, South Mumbai, India \\ ${ }^{2}$ Department of Paediatric Cardiac Anaesthesiology and Intensivist, Wockhardt Hospitals, South Mumbai, India \\ ${ }^{3}$ Director of Pediatric and Congenital Heart Centre and Chief Pediatric Cardio-Thoracic Surgeon, Wockhardt Hospitals, South Mumbai, India
}

Email address:

bhadra81@gmail.com (B. Trivedi)

${ }^{*}$ Corresponding author

\section{To cite this article:}

Bhadra Trivedi, Prasanna Salvi, Manish Chokhandre, Naveed Khan, Ameya Mandrekar, Suresh Joshi. Early Outcomes of Arterial Switch Operation Performed at a New Pediatric Cardiology Center in Mumbai. International Journal of Cardiovascular and Thoracic Surgery. Vol. 5, No. 1, 2019, pp. 12-17. doi: 10.11648/j.ijcts.20190501.13

Received: January 24, 2019; Accepted: March 28, 2019; Published: April 13, 2019

\begin{abstract}
Introduction: The transposition of great arteries (TGA) is one of the main causes of neonatal or early infancy open heart surgeries in pediatric cardiology. The ASO is preferred over the Atrial switch when suitable as the left ventricle remains the systemic ventricle and there are fewer incidences of postoperative arrhythmias. Method: It's a retrospective review of the early surgical outcomes of arterial switch operation performed at the department of pediatric cardiology at Wockhardt Hospital, Mumbai Central, Mumbai from August 2014 to August 2017. Results: During the specified period, a total of 22 children were admitted to the hospital for ASO for TGA. The average age of the patient was 78 days. The mean weight of the children was $3.35 \mathrm{~kg}$ and height was $52.5 \mathrm{~cm}$. Discussion: The early outcome of arterial switch operation at our center is as good as the other well-established centers. The surgical outcome of ASO remained consistent over the last two and a half year. The policy of our institution is to optimize the patients prior to the surgery, may need BAS if the children are of TGA with intact ventricular septum with restricted atrial level shunt group. Conclusion: The review shows the early results of postoperative cases of arterial switch operation from a new center are as encouraging as from the other high volume centers.
\end{abstract}

Keywords: Congenital Heart Disease, Arterial Switch Operation, Transposition Great Arteries, Pediatric Cardiac Surgery

\section{Introduction}

The transposition of great arteries (TGA) is one of the main cause for neonatal or early infancy open heart surgeries in pediatric cardiology. The atrial switch operation Sennings or Mustard - were the options available before Arterial Switch Operation (ASO). The arterial switch operation by Jatene has been the choice of repair for trans position of great arteries with or without the ventricular septal defect since the time of its inception. He first described the surgery in 1975 [1]. The ASO is preferred over the Atrial switch when suitable as the left ventricle remains the systemic ventricle and there are fewer incidences of postoperative arrhythmias [2]. The Lecompte's technique for reconstruction of the right ventricular outflow tract has been accepted as a part of the ASO [3]. ASO is a complex surgery usually performed at a very young age. The surgical results have improved significantly over the last three decades, mainly attributed to improved surgical skills, better intensive care support, and accurate diagnostic capabilities. The accepted early mortality has been as low as $0 \%-5 \%[4,5]$. There are studies in the past suggestive of higher mortality of arterial switch operation at a small volume center or surgeon [6]. The recent study published in 2016 refutes the result and shows that the ASO performed at a new center can have early and midterm results comparable to that of the wellestablished centers $[7,8]$. The objective of this review is to analyze early surgical results of the arterial switch operations performed at our center. 


\section{Method}

It's a retrospective review of the early surgical outcomes of arterial switch operation performed at the department of pediatric cardiology at Wockhardt Hospital, Mumbai Central, Mumbai between August 2014 to August 2017. The medical records were recovered from hospital records. The surgical details were obtained from operation notes. The necessary approval for the retrospective review was obtained from the institutional review board.

\section{Results}

During the specified period, a total of 22 children were admitted to the hospital for ASO for TGA. Out of those, 18 had undergone arterial switch-operation, and one child had undergone Senning's atrial switch operations as the left ventricle was regressed by the time of the surgery. Three children died in the course of treatment. The first child had presented with a diagnosis of d-TGA with cardio-respiratory arrest in the emergency department, which could not be revived. The second child got admitted with d-TGA with intact ventricular septum with small atrial septal defect presented with severe sepsis. The emergency balloon atrial septostomy (BAS) was performed as a life-saving procedure for the same child. The child succumbed to disseminated intravascular coagulation secondary to severe sepsis. The third child was a one-month-old child who had coarctation of aorta along with d-TGA. After sternotomy for corrective surgery for the child, pus discharge from multiple sites was found. The surgery was deferred. The child succumbed to severe sepsis. One child was transferred in from another hospital with a diagnosis of intact septum TGA with a small atrial septal defect with fungal sepsis at the age of 22 days. The BAS was performed, and the child was treated with appropriate antifungal medications for three weeks. The arterial switch operation was performed after the completion of the ant-fungal treatment. Another child required extracorporeal membrane oxygenation (ECMO) support for 91 hours immediately postoperatively in ICU as the left ventricle was failing immediately after the corrective surgery.

Table 1. Demographic details of the study population.

\begin{tabular}{|c|c|c|c|c|c|c|c|c|c|}
\hline \multicolumn{10}{|c|}{ Demographic profiles of the patients } \\
\hline No & $\begin{array}{l}\text { Age } \\
\text { (days) }\end{array}$ & $\begin{array}{l}\text { Weight } \\
\text { (kg) }\end{array}$ & $\begin{array}{l}\text { Height } \\
\text { (cm) }\end{array}$ & $\begin{array}{l}\text { spo2 } \\
(\%)\end{array}$ & gender & Diagnosis (\#) & $\begin{array}{l}\text { Great Arteries } \\
\text { Relationship (*) }\end{array}$ & $\begin{array}{l}\text { Coronaries } \\
\text { Anatomy (@) }\end{array}$ & Surgery (\#\#) \\
\hline 1 & 39 & 3.30 & 54 & 70 & $\mathrm{~m}$ & d-TGA, Mild PS & Ar-RtAn & $1 \mathrm{LCxR}$ & ASO \\
\hline 2 & 39 & 2.20 & 48 & 72 & $\mathrm{~m}$ & d-TGA, Large VSD, ASD, CoA & $\mathrm{AP}$ & $1 \mathrm{LCx} 2 \mathrm{R}$ & $\begin{array}{l}\text { ASO + Closure of VSD + ASD, } \\
\text { Repair of CoA }\end{array}$ \\
\hline 3 & 5 & 2.80 & 47 & 90 & $\mathrm{~m}$ & d-TGA, Small PDA & Ar-RtAn & $1 \mathrm{LCx} 2 \mathrm{R}$ & ASO + Ligation and division of PDA \\
\hline 4 & 23 & 2.90 & 51 & & $\mathrm{f}$ & d-TGA, Large VSD & AP & $1 \mathrm{LCx} 2 \mathrm{R}$ & ASO + VSD Closure \\
\hline 5 & 119 & 3.30 & 53 & 89 & $\mathrm{f}$ & $\begin{array}{l}\text { DORV, Sub-Arterial VSD, Large } \\
\text { ASD, Small PDA }\end{array}$ & $\begin{array}{l}\text { Side by side. } \\
\text { Aorta right }\end{array}$ & 1LCx2R & $\begin{array}{l}\text { ASO, Closure of VSD + ASD, } \\
\text { Ligation and division of PDA }\end{array}$ \\
\hline 6 & 61 & 2.70 & 44 & 76 & $\mathrm{~m}$ & d-TGA, Large VSD + ASD & Ar-RtAn & $1 \mathrm{LCxR}$ & ASO, Closure of VSD + ASD \\
\hline 7 & 48 & 2.90 & 50 & 80 & $\mathrm{~m}$ & d-TGA, Large VSD, ASD & $\begin{array}{l}\text { side by side. Aorta } \\
\text { right }\end{array}$ & $1 \mathrm{LCx} 2 \mathrm{R}$ & ASO, Closure of VSD + ASD \\
\hline 8 & 25 & 3.10 & 51 & 57 & $\mathrm{f}$ & d-TGA, Small ASD, SP BAS & Ar-RtAn & 1LCxR & ASO, SP BAS \\
\hline 9 & 22 & 2.60 & 48 & 74 & $\mathrm{~m}$ & d-TGA, Small ASD, SP BAS & AP & $1 \mathrm{LCx} 2 \mathrm{R}$ & ASO, SP BAS \\
\hline 10 & 18 & 2.90 & 49 & 65 & $\mathrm{~m}$ & d-TGA, Small PDA & AP & 1L2RCx & ASO \\
\hline 12 & 15 & 3.50 & & 55 & $\mathrm{f}$ & d-TGA, Small ASD & Ar-RtAn & 1LCx2R & $\begin{array}{l}\text { Admitted with unstable vitals, Death } \\
\text { pre-op }\end{array}$ \\
\hline 13 & 36 & 3.00 & 52 & 94 & $\mathrm{f}$ & $\begin{array}{l}\text { DORV, Sub-Arterial VSD, Small } \\
\text { ASD }\end{array}$ & Ar-RtAn & $1 \mathrm{LCxR}$ & $\begin{array}{l}\text { Intra-op evaluation - Severe Sepsis, } \\
\text { Corrective surgery deferred. Death }\end{array}$ \\
\hline 14 & 31 & 2.50 & 46 & 72 & $\mathrm{~m}$ & d-TGA, small ASD, Sepsis & Ar-RtAn & $1 \mathrm{LCx} 2 \mathrm{R}$ & $\begin{array}{l}\text { Admitted with sepsis, BAS done, } \\
\text { Died of sepsis }\end{array}$ \\
\hline 15 & 8 & 2.90 & 52 & 66 & $\mathrm{f}$ & d-TGA, Large PDA & AP & $1 \mathrm{LCx} 2 \mathrm{R}$ & ASO, Ligation and division of PDA \\
\hline 16 & 78 & 5.30 & 52 & 65 & $\mathrm{~m}$ & d-TGA, Small ASD & Ar-RtAn & $1 \mathrm{LCx} 2 \mathrm{R}$ & ASO \\
\hline 17 & 217 & 4.30 & 61 & 60 & $\mathrm{~m}$ & d-TGA, Regressed LV & Ar-RtAn & $1 \mathrm{LCxR}$ & Senning's Atrial Switch Operation \\
\hline 18 & 56 & 2.90 & 50 & 65 & $\mathrm{~m}$ & d-TGA, SP BAS & AP & $1 \mathrm{LCxR}$ & ASO + ECMO for 91 hours \\
\hline 19 & 62 & 3.00 & 54 & 45 & $\mathrm{~m}$ & d-TGA, small ASD & Ar-RtAn & 1LR2Cx & ASO \\
\hline 20 & 600 & 7.50 & 75 & 98 & $\mathrm{f}$ & d-TGA, Large VSD, PAH & AP & $1 \mathrm{LCx} 2 \mathrm{R}$ & ASO, VSD closure \\
\hline 21 & 21 & 2.80 & 52 & 72 & $\mathrm{f}$ & d-TGA, Small ASD & Ar-RtAn & $1 \mathrm{LCX} 2 \mathrm{R}$ & ASO, ASD closure \\
\hline 22 & 129 & 4.30 & 59 & 68 & $\mathrm{~m}$ & d-TGA, Large VSD, Large ASD & AP & 1L2RCx & ASO, Closure of VSD and ASD \\
\hline
\end{tabular}

(\#) Diagnosis - d-TGA - d-Transposition of the great arteries; PS-pulmonary stenosis, VSD - Ventricular septal defect, ASD- Atrial septal defect, PDA-Patent ductus arteriosus, DORV-Double outlet right ventricle, LV - Left ventricle, BAS - Balloon Atrial Septostomy

(*) Great Arterial Relationship - Position of the aorta in reference to the pulmonary artery. Ar-Aorta, Rt-Right, An-Anterior, AP - Anterior Posterior

(@) Coronary Anatomy - 1-Facing Sinus 1 and 2-Facing Sinus 2. L-Left main coronary artery, Cx-Circumflex artery, R-Right main coronary artery

(\#\#) Surgery - ASO - Arterial Switch Operation, VSD - a ventricular septal defect, ASD - Atrial septal defect, PDA - Patent ductus arteriosus, ECMO - Extra-

corporeal Membrane Oxygenator 
Table 2. Echocardiogram Diagnosis of the study population.

\begin{tabular}{lll}
\hline \multicolumn{2}{l}{ Cardiac Diagnosis } & \\
\hline No & Diagnosis & Frequency \\
\hline 1 & d-TGA with IVS & 8 \\
2 & d-TGA with IVS with SP BAS & 3 \\
3 & d-TGA with Large VSD and/or PDA & 7 \\
4 & d-TGA with Large VSD with CoA & 1 \\
5 & DORV with large sub-pulmonic VSD & 2 \\
6 & d-TGA with regressed LV & 1 \\
\hline
\end{tabular}

d-TGA - d-transposition of the great arteries, IVS-Intact ventricular septum, SP BAS - Status Post Balloon Atrial Septostomy, VSD - Ventricular septal defect, PDA - Patent ductus arteriosus, CoA - Coarctation of Aorta

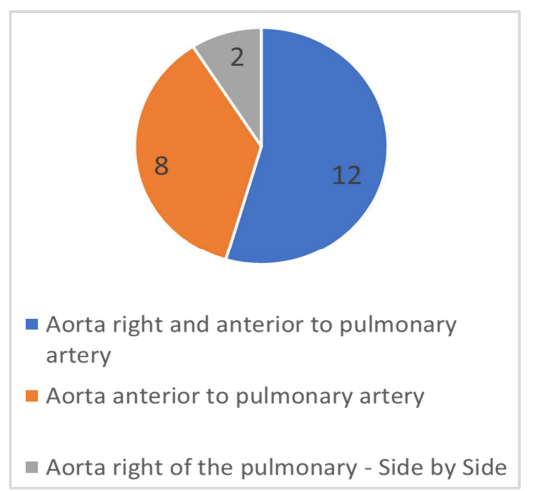

Figure 1. Graph showing the distribution of great arterial relationship in the study population.

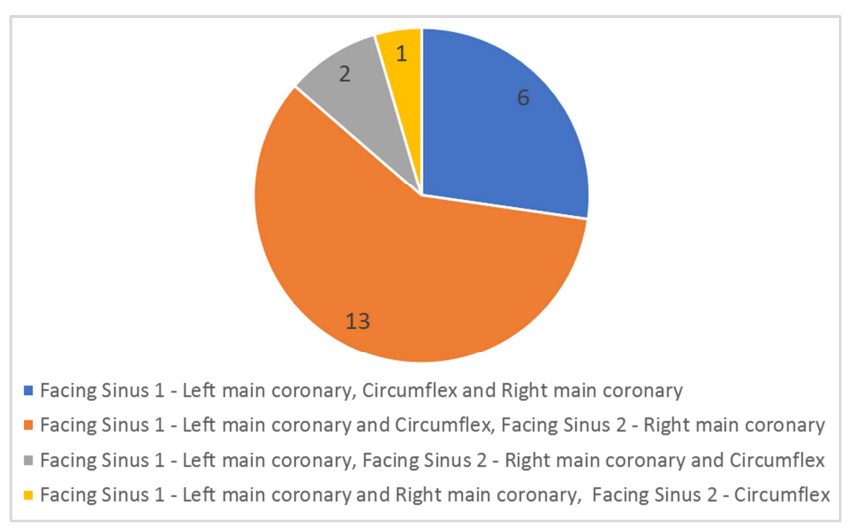

Figure 2. Graph is showing a distribution of coronary anatomy.

The age of children being managed at the hospital presenting with TGA was ranging between 5 days to 600 days with a mean age of 78 days. The mean weight of the children was $3.35 \mathrm{~kg}$ (SD 1.15), and height was $52.5 \mathrm{~cm}$ (SD
$6.5 \mathrm{~cm})$. The body surface area of the studied population ranged from 0.07 to 0.20 with a mean value is 0.09 with $\mathrm{SD}$ of 0.03 . Out of these 22 children 9 were female and 13 were males. Two children presented with severe sepsis had undergone BAS and were being treated by appropriate antibiotics. One of them had undergone a corrective ASO after treatment of sepsis, while the other child succumbed to sepsis.

\section{Surgical details:}

All the surgeries were performed by a single senior pediatric cardiothoracic surgeon. The surgeries were performed using standard median sternotomy. The cardiopulmonary bypass (CPB) was instituted using bi-caval cannulation. The temperature was maintained between $22^{\prime} \mathrm{C}$ to $25^{\prime} \mathrm{C}$ during the operation. The branch pulmonary arteries and aorta were dissected before the aortic cross-clamp. The Del Nido cardioplegia was used for myocardium protection. The neo-aorta was reconstructed first; then the coronaries were trans-located followed by neo pulmonary reconstruction using LeCompte maneuver. The average cardiopulmonary bypass time was 215 minutes, with a minimum of 144 minutes and maximum of 312 minutes with SD of 41 minutes. One child required ECMO support, so the CPB time increased to 312 minutes. The mean cross-clamp time is 139 minutes with SD of 28 minutes. The modified ultrafiltration was done in 6 children. It ranged from 10 to 25 minutes. Total 11 children were shifted to ICU with an open chest, which was closed during next 1 or 2 days. A 56 days old child with d-TGA with intact ventricular septum with a small atrial septal defect, who had undergone BAS, had dilatation and poor functioning of the left ventricle immediately after the corrective surgery in operation theatre. It was decided to provide ECMO support. The ECMO support was continued for 91 hours postoperatively in ICU before it was gradually weaned off. The average hours of intubation are 114 hours, ranging from 23 hours to 300 hours. The average stay in ICU was days, ranging from 2 days to 43 days. Three children developed sepsis during the postoperative course in ICU. The children were treated with appropriate antibiotics based on culture and sensitivity pattern of the blood culture report. Total 18 children needed peritoneal dialysis catheter. Ten had left atrial line secured for monitoring of left atrial pressure. The lines were removed between 3-5 days. The total postoperative ward stays averaged at 6 days with a maximum stay of 15 days.

Table 3. Summary of results of the review.

\begin{tabular}{|c|c|c|c|c|c|}
\hline Analysis & mean & Median & SD & minimum & $\max$ \\
\hline Weight (kg) & 3.35 & 2.95 & 1.15 & 2.2 & 7.5 \\
\hline Height $(\mathrm{cm})$ & 52.48 & 52 & 6.49 & 44 & 75 \\
\hline BSA & 0.09 & 0.08 & 0.03 & 0.07 & 0.19 \\
\hline Age in day & 78.36 & 39 & 126.32 & 5 & 600 \\
\hline HOI* (Hours) & 114.11 & 112 & 74.58 & 23 & 300 \\
\hline CPB** (Minutes) & 215.11 & 214 & 42.68 & 144 & 312 \\
\hline XCL ${ }^{\#}$ (Minutes) & 139.58 & 136 & 28.22 & 93 & 197 \\
\hline ICU stay (days) & 10.71 & 9 & 8.61 & 2 & 43 \\
\hline Ward stay (days) & 6.28 & 6 & 2.91 & 3 & 15 \\
\hline
\end{tabular}

*HOI - Hours of intubation. ** CPB - Cardio-Pulmonary Bypass. \# XCL - Cross-Clamp Time. \#\# MUF - Modified Ultrafiltration 


\section{Discussion}

The newly established pediatric cardiology program in reference was started in August 2014. During the specified period of August 2014 to August 2017, there was no reported early death associated with arterial switch operation. The three deaths occurred, were in the pre-operative patients; among them, two had severe sepsis. One child presented with cardio-respiratory arrest in the emergency department and could not be revived. The early mortality of $0 \%$ is matching the expected mortality of up to 5\% [9]. The early outcome of arterial switch operation at the center was found comparable to the other well-established centers, which is contrary to what was observed in the literature review. The contemporary literature showed that the surgical outcome of arterial switch operation performed at the new centers is associated with higher morbidity and mortality [10-12]. The surgical outcome of ASO at the current center remained consistent over the last two and a half year. The study published in 2012 suggested that the arterial switch operation was a complex procedure' and the morbidity and mortality could be minimized by continuous learning and adapting improved peri-operative management of children. The article also mentioned about the effect the years of surgical experience of the surgeon had on the overall outcome of the surgery, where the center did not report any morality on ASO after 1994 to 1999 , compared to $15 \%$ mortality before 1994 [13]. A similar experience was also documented by Shim et al. in 2016, where the center did not report any cardiac death since 1998 [7].

As a policy of the current unit the children with an intact septum, presented with a severe form of sepsis underwent BAS and were treated with optimum antibiotics prior to the surgery. The smallest child among the study group weighed $2.2 \mathrm{~kg}$ and was 22 days old with severe cyanosis. He underwent BAS and was stabilized for 8 days before ASO. This approach helped in achieving better results in borderline cases where the infection was a concern. A lot of children get referred to the pediatric cardiac center in review from the other peripheral centers in sub-optimum conditions. Other centers have reported higher mortality- up-to $10 \%$ in children being operated as soon as possible [14]. The youngest child operated for arterial switch operation at the current pediatric cardiology center was 5 days who had TGA with an intact septum. The policy of the current institution was to optimize the patients prior to the surgery, may need BAS if the children are of TGA with intact ventricular septum with restricted atrial level shunt group. The contemporary literature review suggests that the youngest child operated for the arterial switch was of 6 hours of life, where the surgery was performed under deep hypothermic circulatory arrest and low-flow perfusion [15]. A review of 400 children by Khairy showed that the median age for arterial switch operation was 5 days [9]. The average age of the child undergoing arterial switch operation with the intact ventricular septum in the existing study group was 31 days. This can be attributed to the delayed diagnosis and referral of the children to our center. The review does not report any adverse outcome among the group with TGA with intact ventricular septum. There were concerns about left ventricular preparedness in TGA with intact septum beyond the age of 3 weeks [16]. The surgical decision for a child with d-TGA with an intact septum, presenting beyond 3-4 weeks is widely debated between Atrial and Arterial Switch for the doubt of borderline left ventricle preparedness $[17,18]$. Ismail et al. showed encouraging result for the arterial switch operation performed for TGA with intact septum with good early outcome [19]. There was no incidence of arrhythmias in the postoperative arterial switch operation found in the existing review. The reported incidence of junctional ectopic arrhythmias and other arrhythmias as high as $62 \%$ [20]. The cross-clamp time and the total cardiopulmonary bypass (CPB) times were found to be significantly higher in the study population compared to other large centers [21, 22]. The average CPB time was 200 minutes in the current review, Qamar reported that the mean CPB time at their center was 121 minutes for TGA with an intact septum and 139 minutes for TGA with ventricular septal defect [23]. Another study from India reported mean CPB time of 94.7 min $+/-21.3$ minutes and cross-clamp time of 53.2 minutes $+/-8.1$ minutes [24]. Ahmed et all reported median CPB time of 202 minutes in their series [25]. The cross-clamp time has been recognized as an independent predictor of the postoperative outcome of ASO [26]. The average crossclamp time for the current group was 139 minutes. The crossclamp time was higher than the reported 78 minutes for the hypothermic group and 79 minutes for the normothermic group by Philippe Pouard [27]. Anderson Also reported average cross-clamp time of 77 minutes [28]. Though the average CPB time and cross-clamp times reported in this review were higher than the other series, there was no immediate morbidity associated with it.

Dibardino et al reported $1.6 \%$ of early mortality of arterial switch operation in neonate [29]. The study did not reveal any mortality during the arterial switch operation.

There were no adverse events associated with coronary insufficiency reported in this review. The coronary transfer was done without any complications. The similar result was found during the study by Zuhab et al who showed that the coronary anatomy did not affect the surgical outcome [23].

\section{Conclusion}

The review shows the early results of postoperative cases of arterial switch operation from a newly established center were as encouraging as from the other well-established centers. The results were heavily dependent on the surgical experience, technique, post-operative ICU support, and case selection, including pre-operative stabilization with BAS. Continues assessment of the existing surgical outcome has led to the significant improvement in peri-operative management of Arterial Switch Operation. The current 
review shows that the newly established Pediatric cardiac centers can have excellent surgical outcomes of arterial switch operations even in limited resources with a proper surgical plan and peri-operative care

\section{Conflict of Interest}

All the authors do not have any possible conflicts of interest.

\section{References}

[1] Jatene AD, Fontes VF, Paulista PP, de Souza LC, Neger F, Galantier $M$, et al. Successful anatomic correction of transposition of the great vessels. A preliminary report. Arquivos brasileiros de cardiologia. 1975; 28 (4): 461-64.

[2] Quaegebeur JM, Rohmer J, Ottenkamp J, Buis T, Kirklin JW, Blackstone EH, et al. The arterial switch operation. An eightyear experience. The Journal of thoracic and cardiovascular surgery. 1986; 92 (3 Pt 1): 361-84.

[3] Lecompte Y, Neveux JY, Leca F, Zannini L, Tu TV, Duboys Y, et al. Reconstruction of the pulmonary outflow tract without prosthetic conduit. The Journal of thoracic and cardiovascular surgery. 1982; 84 (5): 727-33.

[4] Prandstetter C, Hofer A, Lechner E, Mair R, Sames-Dolzer E, Tulzer G. Early and mid-term outcome of the arterial switch operation in 114 consecutive patients: A single centre experience. Clinical research in cardiology: official journal of the German Cardiac Society. 2007; 96 (10): 723-9.

[5] Stoica S, Carpenter E, Campbell D, Mitchell M, da Cruz E, Ivy $\mathrm{D}$, et al. Morbidity of the arterial switch operation. The Annals of thoracic surgery. 2012; 93 (6): 1977-83.

[6] Karamlou T, Jacobs ML, Pasquali S, He X, Hill K, O'Brien S, et al. Surgeon and center volume influence on outcomes after arterial switch operation: analysis of the STS Congenital Heart Surgery Database. The Annals of thoracic surgery. 2014; 98 (3): 904-11.

[7] Shim MS, Jun TG, Yang JH, Park PW, Kang IS, Huh J, et al. Current expectations of the arterial switch operation in a small volume center: a 20-year, single-center experience. Journal of cardiothoracic surgery. 2016; 11: 34 .

[8] Rosenthal GL, Wilson PD, Permutt T, Boughman JA, Ferencz C. Birth weight and cardiovascular malformations: a population-based study. The Baltimore-Washington Infant Study. American journal of epidemiology. 1991; 133 (12): 1273-81.

[9] Khairy P, Clair M, Fernandes SM, Blume ED, Powell AJ, Newburger JW, et al. Cardiovascular outcomes after the arterial switch operation for D-transposition of the great arteries. Circulation. 2013; 127 (3): 331-9.

[10] Rodriguez Puras MJ, Cabeza-Letran L, Romero-Vazquianez M, Santos de Soto J, Hosseinpour R, Gil Fournier M, et al Mid-term morbidity and mortality of patients after arterial switch operation in infancy for transposition of the great arteries. Revista espanola de cardiologia (English ed). 2014; 67 (3): 181-8.

[11] Manso PH, Amaral FT, Junior TJ, Jurca MC, Haddad J, Vicente WV, et al. Outcomes of Patients After Arterial Switch
Operation: 18 Years of Experience in a Single MediumVolume Center. Pediatric cardiology. 2015; 36 (8): 1657-61.

[12] Fricke TA, d'Udekem Y, Richardson M, Thuys C, Dronavalli M, Ramsay JM, et al. Outcomes of the arterial switch operation for transposition of the great arteries: 25 years of experience. The Annals of thoracic surgery. 2012; 94 (1): 13945.

[13] Popov AF, Tirilomis T, Giesler M, Oguz Coskun K, Hinz J, Hanekop GG, et al. Midterm results after arterial switch operation for transposition of the great arteries: a single centre experience. Journal of cardiothoracic surgery. 2012; 7: 83.

[14] Roussin R, Belli E, Bruniaux J, Demontoux S, Touchot A, Planche C, et al. Surgery for transposition of the great arteries in neonates weighing less than 2,000 grams: a consecutive series of 25 patients. The Annals of thoracic surgery. 2007; 83 (1): 173-7; discussion 7-8.

[15] Xu ZW, Liu JF, Zhang HB, Zheng JH, Yan Q, Qiu LS, et al. [Analysis surgical results of 113 patients with complete transposition of the great arteries]. Zhonghua wai ke za zhi [Chinese journal of surgery]. 2007; 45 (12): 801-4.

[16] Foran JP, Sullivan ID, Elliott MJ, de Leval MR. Primary arterial switch operation for transposition of the great arteries with intact ventricular septum in infants older than 21 days. Journal of the American College of Cardiology. 1998; 31 (4): 883-9.

[17] Williams WG, McCrindle BW, Ashburn DA, Jonas RA, Mavroudis C, Blackstone EH. Outcomes of 829 neonates with complete transposition of the great arteries 12-17 years after repair. European journal of cardio-thoracic surgery: official journal of the European Association for Cardio-thoracic Surgery. 2003; 24 (1): 1-9; discussion -10 .

[18] Yacoub MH, Radley-Smith R, Maclaurin R. Two-stage operation for anatomical correction of transposition of the great arteries with intact interventricular septum. Lancet (London, England). 1977; 1 (8025): 1275-8.

[19] Ismail SR, Kabbani MS, Najm HK, Abusuliman RM, Elbarbary M. Early outcome for the primary arterial switch operation beyond the age of 3 weeks. Pediatric cardiology. 2010; 31 (5): 663-7.

[20] Tobler D, Williams WG, Jegatheeswaran A, Van Arsdell GS, McCrindle BW, Greutmann M, et al. Cardiac outcomes in young adult survivors of the arterial switch operation for transposition of the great arteries. Journal of the American College of Cardiology. 2010; 56 (1): 58-64.

[21] Hraska V, Podnar T, Kunovsky P, Kovacikova L, Kaldararova M, Horvathova E, et al. Is a learning curve for arterial switch operation in small countries still acceptable? Model for cooperation in Europe. European journal of cardio-thoracic surgery: official journal of the European Association for Cardio-thoracic Surgery. 2003; 24 (3): 352-7.

[22] Karl TR, Hall S, Ford G, Kelly EA, Brizard CPR, Mee RBB, et al. Arterial switch with full-flow cardiopulmonary bypass and limited circulatory arrest: Neurodevelopmental outcome. The Journal of thoracic and cardiovascular surgery. 2004; 127 (1): 213-22.

[23] Qamar ZA, Goldberg CS, Devaney EJ, Bove EL, Ohye RG. Current risk factors and outcomes for the arterial switch operation. The Annals of thoracic surgery. 2007; 84 (3): 8718; discussion 8-9. 
[24] Bisoi AK, Sharma P, Chauhan S, Reddy SM, Das S, Saxena A, et al. Primary arterial switch operation in children presenting late with d-transposition of great arteries and intact ventricular septum. When is it too late for a primary arterial switch operation? European journal of cardio-thoracic surgery: official journal of the European Association for Cardiothoracic Surgery. 2010; 38 (6): 707-13.

[25] Mekkawy A, Ghoneim A, El-Haddad O, Photiadis J, Elminshawy A. Predictors of early outcome of arterial switch operation in patients with D-TGA. Journal of the Egyptian Society of Cardio-Thoracic Surgery. 2017; 25 (1): 52-7.

[26] Lalezari S, Bruggemans EF, Blom NA, Hazekamp MG. Thirty-year experience with the arterial switch operation. The Annals of thoracic surgery. 2011; 92 (3): 973-9.
[27] Pouard P, Mauriat P, Ek F, Haydar A, Gioanni S, Laquay N, et al. Normothermic cardiopulmonary bypass and myocardial cardioplegic protection for neonatal arterial switch operation. European Journal of Cardio-Thoracic Surgery. 2006; 30 (5): 695-9.

[28] Anderson BR, Ciarleglio AJ, Hayes DA, Quaegebeur JM, Vincent JA, Bacha EA. Earlier arterial switch operation improves outcomes and reduces costs for neonates with transposition of the great arteries. Journal of the American College of Cardiology. 2014; 63 (5): 481-7.

[29] Dibardino DJ, Allison AE, Vaughn WK, McKenzie ED, Fraser CD, Jr. Current expectations for newborns undergoing the arterial switch operation. Annals of surgery. 2004; 239 (5): 588-96; discussion 96-8. 